\section{Military Technical College Kobry El-Kobbah, Cairo, Egypt.}

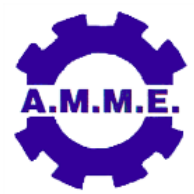

\title{
STATISTICAL MODELING FOR ALUMINA LASER SINTERING
}

\author{
E. M. Fayed ${ }^{1,2}$, A.S. Elmesalamy ${ }^{1}$, M. Sobih ${ }^{1}$ and Y. I. El-Shaer ${ }^{1}$
}

\begin{abstract}
Selective laser sintering processes is one of the most additive manufacturing processes. This process characterized by its interaction parameters and their sever influence in the process output. The most significant parameters were found to be laser power, laser scanning speed. The main objectives of this work are to understand the effect of these parameters and their interaction on the process quality and physical properties of ceramic laser-sintered components; and to introduce a statistical model that assist in determining the optimal values of the significant parameters and prediction of corresponding sintering responses, aiming reduce the consumed time for manufacturing and consequently the cost of the component. Experiments were carried out using a pulsed Nd: YAG laser machine. Design of experiments and statistical modeling techniques were employed using response surface methodology. The effects of the two controllable variables, laser power, laser scanning speed and their interaction on the laser sintered line width, monolayer thickness, surface roughness and density were investigated. The results indicate that the developed model can predict the responses adequately within the limits of sintering parameters being used.
\end{abstract}

\section{KEYWORDS}

Additive manufacturing, selective laser sintering; statistical modeling; multi-objective optimization; and ceramics.

1 Egyptian Armed Forces.

${ }^{2}$ Corresponding author, Email: eslamfayed2009@gmail.com, Tel.: +2010 91277080 


\section{INTRODUCTION}

Selective laser sintering (SLS) is an additive manufacturing technique where parts are fabricated layer by layer. Powder layers are deposited by a roller or a scraper and a laser beam is used as a heating source to locally heat and sinter the deposited powder layer according to predetermined geometries. The sequence of powder deposition and laser scanning is repeated until the part is completed [1]. This process is one of the popular rapid prototyping and additive manufacturing processes for complex components with diverse material properties in reduced time compared to traditional sintering that make it has a wide range of applications and also is highly focused by industries owing to the diversity of SLS forming material, whereas, any powders that can be bonded together by heating can be used as raw materials for SLS [2].

Ceramics become a possible alternative to the common metallic materials for a lot of industries. Since the ceramic materials have the advantage of good creep resistance, high temperature stability, high hardness, high mechanical strength, low elongation under application of stress, low density, excellent wear resistance and chemical inertness, which make them suitable for use in many applications, [3]. The majority of researches investigated and studied the effect of the most effective parameters on a several responses such as density, surface roughness, line width, monolayer thickness, monolayer deformation, strength and microstructure with different materials. The results included that; laser power is directly proportional with sintered part density, surface roughness, sintered line width, monolayer thickness and monolayer deformation. Moreover, the laser scanning speed is inversely proportional with all these responses, [2, 4-9].

Betrand et. al [10] used design of experiment to identify only the influent process parameter (powder characteristics, powder layering and laser manufacturing strategy) to obtain high quality ceramic component (density and microstructure). The results include that the processing of pure yttria zirconia powder by SLS facilities without additives element is possible and the density of $\mathrm{ZrO}_{2}$ component improved by increasing the powder bed density.

Although the preceding research investigate the influence of laser power and scanning speed, Understanding the influence of these parameters and their interaction in detail to obtain high quality ceramic component (layer surface roughness, monolayer thickness and line width) and high physical properties (density) is still a point of weakness,[2, 4-7]. Implementing a statistical model to represent the significant parameters, understand the interaction influence of the parameters on the response, and optimize the process parameters have not been investigated yet, [10].

The main objective in this work is to establish a statistical model to investigate the significant process parameters; understand the effect of these parameters and their interaction on the quality and the density of ceramic laser-sintered components; predict sintering responses through mathematical model; and finally to optimize the investigated parameters. 


\section{EXPERIMENTAL STUDY}

The laser system used in the experiments was a pulsed Nd: YAG laser (LUMONICS JK 700 laser machine) with maximum laser power of $330 \mathrm{~W}$ and wavelength of 1.064 $\square \mathrm{m}$ and can be focused to a diameter of $0.67 \mathrm{~mm}$ at focal plane which is $1 \mathrm{~mm}$ underneath the gas nozzle. The laser beam is moved over the powder surface according to the predefined 2D pattern using a 3-D CNC table. The laser sintering process should be carried out at the defocused plane to cover big area in small time and to avoid the formation of plasma, [11], which causes removing of the powder particles. So the laser nozzle plane was adjusted at height of $30 \mathrm{~mm}$ above the powder surface.

The ceramic material used was a high purity alumina $\left(\mathrm{Al}_{2} \mathrm{O}_{3}\right)$ with a mean particle size of $(4: 8) \mu \mathrm{m}$. Alumina powder was pressed by uniaxial dry pressing at $50 \mathrm{MPa}$ using a mild steel die assembly and uniaxial press (SANTEC 100 ton hydraulic press, India) into square layer of $50 \times 50 \mathrm{~mm}$, Fig. (1). Then the sample is ready for sintering process.

A series of screening experiments or runs were carried out on the alumina powder to determine the window of acceptance in which the sintering is successfully accomplished and to determine the maximum and minimum limits of both control factors (laser power from $150 \mathrm{~W}$ to $300 \mathrm{~W}$ at laser scanning speed from $60 \mathrm{~mm} / \mathrm{min}$ to $180 \mathrm{~mm} / \mathrm{min}$ ).

The dimension of the monolayer which includes the line width and layer thickness is measured by using Mitutoyo toolmaker microscope. The surface roughness of the laser sintered monolayer was determined using surface roughness meter (Mitutoyo SJ.201), the average value of ten measurements was considered for each monolayer. The physical properties in terms of bulk density were determined using liquid displacement technique (Archimedes) by using METTLER TOLEDO weight measurement.

Design of experiment (DOE) was used mainly to minimize the number of runs, which consequently reduce the time and cost of the experiments. Furthermore, mathematical model can be implemented for each response that represents the phenomena and finally applying multi-objective optimization to obtain the overall optimum parameters for the applied process.

Maximum and minimum values of each factor were obtained from the preliminary experiments and used to design the experiment matrix that consist of ten experiments according to factorial (2k), axial (2k) and two center point; where $\mathrm{k}$ is the number of factors; as shown in Table 1.

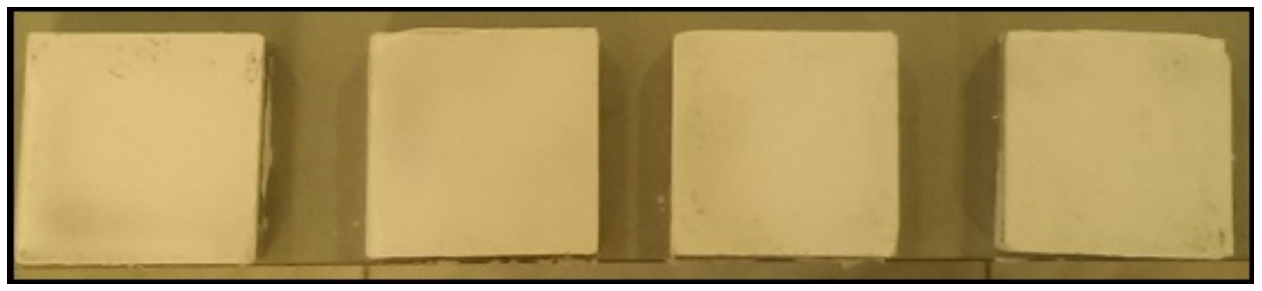

Fig. (1). Compressed alumina 50 x $50 \mathrm{~mm}$ sample. 
Table 1. Experimental parameters obtained from DOE.

\begin{tabular}{c|c|c} 
Run & Laser power $(\mathrm{W})$ & Laser scanning speed $(\mathbf{m m} / \mathbf{m i n})$ \\
\hline $\mathbf{1}$ & 230 & 122.50 \\
$\mathbf{2}$ & 230 & 151.25 \\
$\mathbf{3}$ & 265 & 151.25 \\
$\mathbf{4}$ & 195 & 93.750 \\
$\mathbf{5}$ & 300 & 122.50 \\
$\mathbf{6}$ & 150 & 122.50 \\
$\mathbf{7}$ & 230 & 180.00 \\
$\mathbf{8}$ & 265 & 93.750 \\
$\mathbf{9}$ & 195 & 151.25 \\
$\mathbf{1 0}$ & 230 & 65.000 \\
\hline
\end{tabular}

\section{STATISTICAL MODELING}

Statistical modeling is one of the most efficient tools to study, optimize and predict processing parameters with minimum number of experiments, $[12,13]$. Response surface methodology (RSM) is one of the most applied methods of statistical modeling. It was introduced by Box and Wilson in 1951, $[13,14]$. RSM is a good approach to describe the process and to find the optimal value of the response. It consists of set of mathematical and statistical tools that can used to model the response as function of input factors combinations, optimize, and predict the responses. It is used in development of an adequate functional relation between a response of interest $y$, and input variables denoted by $x_{i}, x_{j}$ as in eq. 1 , which represents general form of polynomial [13]:

$$
y=\varepsilon_{0}+\sum_{i=1}^{k} \beta_{i} x \sum_{i<j} \sum_{i=1}^{k} \beta_{i j} x_{i} x j+\sum_{i=1}^{k} \beta_{i i} x_{i}^{2}+\beta_{0},
$$

where, $\varepsilon_{o}$ is a random experimental error, $\beta$ is a vector of $p$ unknown coefficients, $\left(\beta_{o}\right)$ is response at center, $\beta_{i}$ is coefficient of main linear effect $\beta_{i j}$ is coefficient of two linear factor interaction, and $\beta_{i i}$ is coefficient of quadratic factor.

\section{Modeling Approach}

The experiment sub-design technique of RSM is called Central Composite Design (CCD). It used for estimating second order response surfaces, which could also be used to optimize the responses of interest in the process. The CCD consists of three types of design points (central, axial, and factorial points $[13,15]$. It has three or five level experimental plan. The design depends on applying one run or more at each point of the design matrix. For $k$ factors, there are $2^{k}$ factorial points, and $2 k$ axial points, and 
one central point. The center point is separated by $\alpha$, to the axial points, and unit to factorial points, $[13,15]$. In our investigation, the 5-level experimental plan was used for implementing design matrix. The working ranges for each factor, laser power $(A)$ and laser scanning speed (B) are shown in Table 2.

Table 2. Factor Levels.

\begin{tabular}{|c|c|c|c|c|c|}
\hline Variable & Level $1(-\alpha)$ & Level $2(-1)$ & Level3 (0) & Level 4 (1) & Level $5(\alpha)$ \\
\hline$A(W)$ & 160 & 195 & 230 & 265 & 300 \\
\hline $\mathrm{B}(\mathrm{mm} / \mathrm{min})$ & 65 & 93.75 & 122.50 & 151.25 & 180 \\
\hline
\end{tabular}

The implemented model was used to establish a relationship between control variables, and responses. The studied responses are line width, monolayer thickness, layer surface roughness and density. It also determines individual and interacting significant factors and optimize process parameters to achieve peak performance (maximize or minimize) response according to required optimization criteria.

\section{Validation of Models}

Analysis of variance (ANOVA) is an efficient tool to test the response surface model, $[13,16,17]$. ANOVA results show the significance of the models, which are tested against regression. F-test was applied on each term of the model to check for significance levels, [13]. The $\mathrm{R}^{2}$, and the adjusted $\mathrm{R}^{2}$ values are other two criteria used to indicate the adequacy of a fitted regression model, $[13,18] . R^{2}$ is a measure of the variation around the mean explained by the model and adjusted $R^{2}$ is generally best indicator of the fit quality when we compare two models. The ranges of the $\mathrm{R}^{2}$ values for the implemented models are (94.9:99.1) \%, and adjusted $R^{2}$ are $(86: 97.9) \%$. These values indicate that models can be used to navigate the design space. Adequate precision parameter measures the signal to noise ratio for each model. A ratio greater than 4 indicates that model has acceptable signal, [13]. Adequate precision values ranges from 9.7 to 27.4 are obtained for the models. Scatter diagrams were used also for models validity against regression, perturbation curves and response surface graph are represented for each model.

\section{RESULTS AND DISCUSSIONS}

The experiments output results according to design matrix were qualified and discussed through 4 models. The main objective for these models is to optimize and predict processing parameters of laser sintering and their corresponding responses. The implemented models and output results are discussed in details in the following sections.

\section{Laser Sintered Line Width Model (LW)}

Line width, is the width of the one pass laser-sintered vector. It is observed that the 
width of laser-sintered vectors is wider at higher laser power and/or reduced laser scanning speed, Fig. (2). At this stage of the investigation, the objective of this model was to maximize the width of laser sintered vectors to reduce the estimated time for covering large area.

Line width model and the model verification are given in analysis of variance, Table 3. The ANOVA ( $F$ test) results indicate that the line width model is significant model. Model validation measures are given as $\mathrm{R}^{2}=99.07 \%$, Adj $\mathrm{R}^{2}=97.90 \%$, and Adeq Precision 27.422. These values represent adequate signals from the model, and it can be used to navigate the whole design space. The scatter diagram represents the actual against predicted values, Figure 3 . Most of the points have a small deviation from diagonal line between actual and predicted values. This indicates a good fit for the developed model, [18].

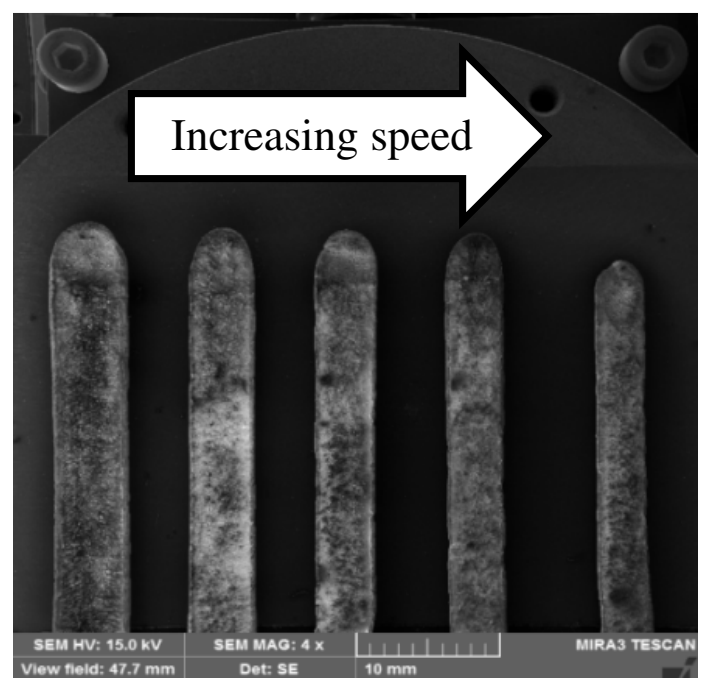

Fig. (2). Width of laser sintered vectors at laser power $230 \mathrm{~W}$ and scanning speed starting from left $60,80,100,120,150 \mathrm{~mm} / \mathrm{min}$.

Table 3: ANOVA table for line width.

\begin{tabular}{c|c|c|c|c|c|c} 
Source & $\begin{array}{c}\text { Sum of } \\
\text { square }\end{array}$ & DF & $\begin{array}{c}\text { Mean } \\
\text { square }\end{array}$ & F value & $\begin{array}{c}\text { P-value } \\
\text { Prob }>\text { F }\end{array}$ & \\
\hline Model & 1.05 & 5 & 0.21 & 84.77 & 0.0004 & Significant \\
A & 0.35 & 1 & 0.35 & 143.52 & 0.0003 & \\
B & 0.6 & 1 & 0.6 & 241.62 & $<0.0001$ & \\
AB & $2.704 \mathrm{E}-003$ & 1 & $2.704 \mathrm{E}-003$ & 1.09 & 0.3545 & \\
A $^{2}$ & 0.012 & 1 & 0.012 & 4.70 & 0.0961 & \\
B $^{2}$ & 0.012 & 1 & 0.012 & 4.80 & 0.0937 & \\
Residual & $9.880 \mathrm{E}-003$ & 4 & $2.470 \mathrm{E}-003$ & & \\
Cor. total & 1.06 & 9 & & & \\
\hline
\end{tabular}




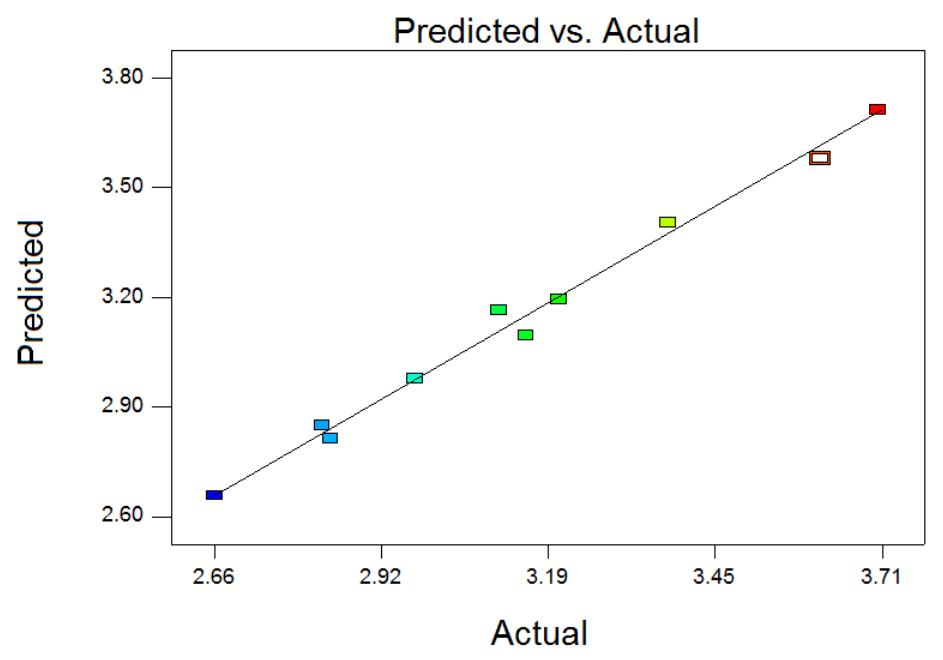

Fig. (3). Predicted and actual values of line width.

Fig. (4) shows the perturbation plot for the laser-sintered line width model. It illustrates the overall influence of the control. Laser-sintered line width is inversely proportional to Laser scanning speed, however laser-sintered line width is directly proportional with laser power. The average value of the laser-sintered line width is more than $3.6 \mathrm{~mm}$ at a scanning speed of $93.75 \mathrm{~mm} / \mathrm{min}$ and a laser power of $256 \mathrm{~W}$. By increasing the scanning speed to $151.25 \mathrm{~mm} / \mathrm{min}$ and decreasing the laser power to $195 \mathrm{~W}$, the average value of the laser-sintered line width decreased to $2.8 \mathrm{~mm}$. This is because increasing laser power and/or reducing laser scanning speed leads to an increase of the power input to the melt pole consequently increases its temperature and hence the volume of the molten powders increases. Therefore, decreasing the scanning speed and increasing the laser power are the key factors for maximizing the laser-sintered line width, which reduce the consuming time to cover the sintered area.

The laser power and laser scanning speed have approximately the same significance on the laser-sintered line width. Fig. (5) shows the response surface graph. It indicates that laser-sintered line width increase is more sensitive to laser power at low speed. Also, it is more sensitive to scanning speed at high laser power. These results confirm the model general trends as shown in the perturbation curve.

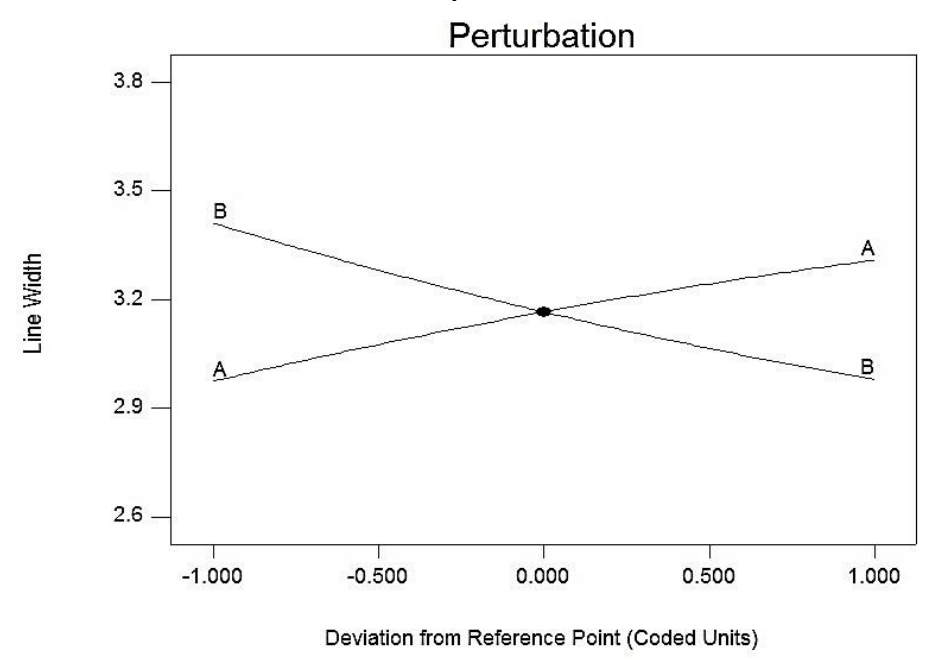

Fig. (4). Perturbation curve for laser-sintered line width model. 


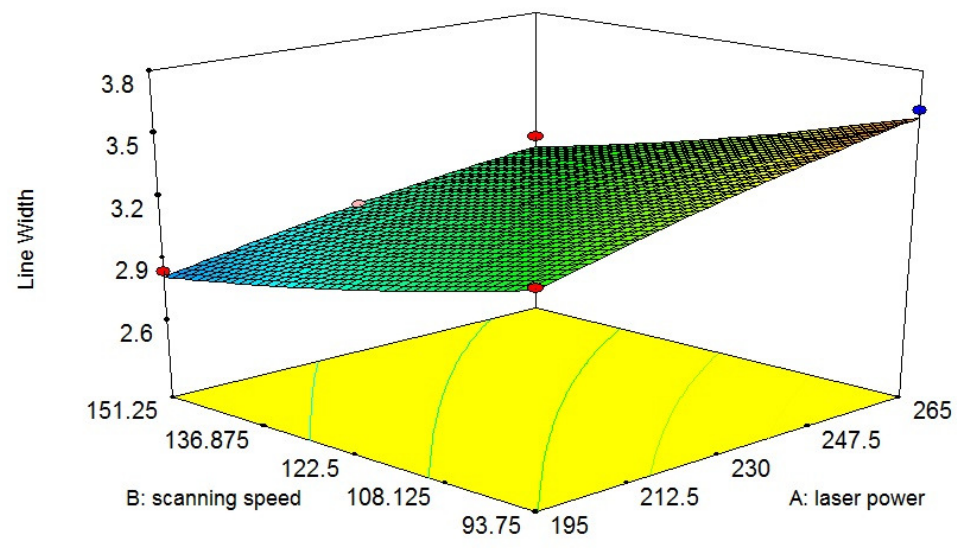

Fig. (5). Response surface for laser-sintered line width model.

\section{Laser-Sintered Layer Thickness Model (LT)}

Layer thickness, is the maximum thickness can be sintered by one pass of laser beam on the ceramic layer. It is observed that the monolayer is thicker at higher laser power and/or reduced laser scanning speed, Fig. (6). The objective of the proposed model is to maximize the thickness of laser sintered layers to reduce the consumed time for covering the sintered volume and building up the sintered part.

The ANOVA result for layer thickness model indicates that the model is significant as shown in Table 4 . Model validation measures are given as $R^{2}=94.98 \%$, Adj $R^{2}=$ $88.71 \%$, Adeq Precision 12.374.

Consequently, the model can represent the data point easily in the design space. The scatter diagram represents the actual against predicted values, Fig. (7). Most of the points have a small deviation from diagonal line between actual and predicted values. This indicates a good fit for the developed model.

Fig. (8) shows the perturbation plot for the laser-sintered layer thickness model. It illustrates the overall influence of the control parameters. Laser-sintered layer thickness is inversely proportional to laser scanning speed while laser-sintered layer thickness is directly proportional with laser power. The average value of the lasersintered layer thickness is more than $0.9 \mathrm{~mm}$ at a scanning speed of $93.75 \mathrm{~mm} / \mathrm{min}$ and a laser power of $256 \mathrm{~W}$. By increasing the scanning speed to $151.25 \mathrm{~mm} / \mathrm{min}$ and

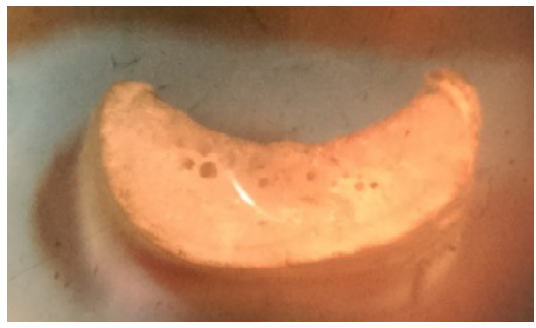

(a)

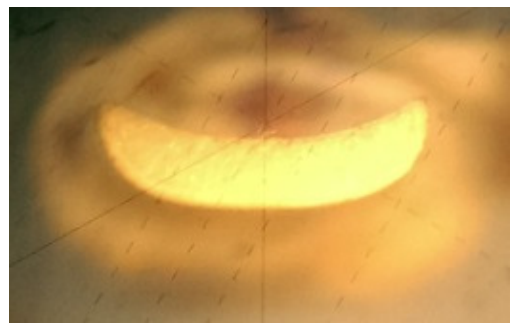

(b)

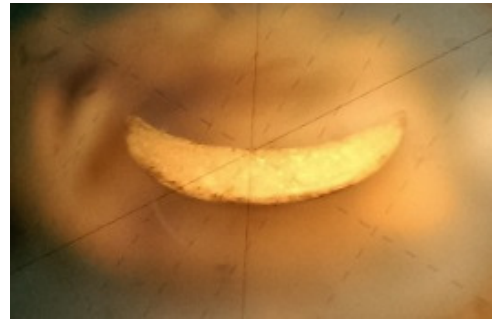

(c)

Fig. (6). Laser sintered monolayer thickness at laser power $230 \mathrm{~W}$, and different scanning speeds (a, b, c) 40, 120 and $180 \mathrm{~mm} / \mathrm{min}$, respectively. 
Table 4 : ANOVA table for monolayer thickness.

\begin{tabular}{c|c|c|c|c|c|c} 
Source & $\begin{array}{c}\text { Sum of } \\
\text { square }\end{array}$ & DF & $\begin{array}{c}\text { Mean } \\
\text { square }\end{array}$ & F value & $\begin{array}{c}\text { P-value } \\
\text { prob }>\text { F }\end{array}$ & \\
\hline Model & 0.40 & 5 & 0.079 & 15.14 & 0.0105 & Significant \\
A & 0.076 & 1 & 0.076 & 14.52 & 0.0189 & \\
B & 0.23 & 1 & 0.23 & 45.00 & 0.0026 & \\
AB & $3.610 \mathrm{E}-004$ & 1 & $3.610 \mathrm{E}-004$ & 0.069 & 0.8056 & \\
A $^{2}$ & $1.697 \mathrm{E}-004$ & 1 & $1.697 \mathrm{E}-004$ & 0.032 & 0.8657 & \\
$\mathbf{B}^{2}$ & 0.046 & 1 & 0.046 & 8.89 & 0.0407 & \\
Residual & 0.021 & 4 & $5.222 \mathrm{E}-003$ & & & \\
Cor. total & 0.42 & 9 & & & & \\
\hline
\end{tabular}

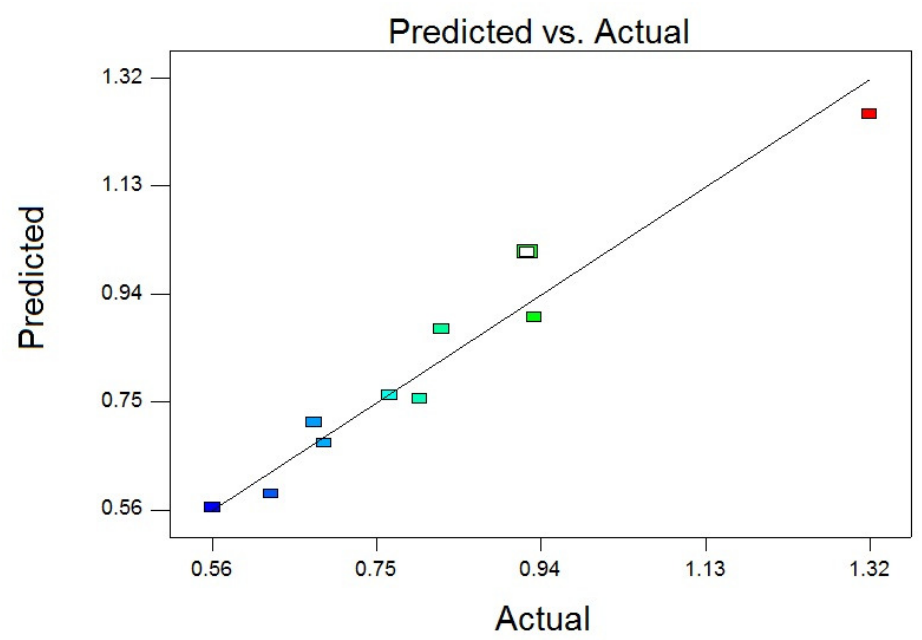

Fig. (7). Predicted and actual values layer thickness.

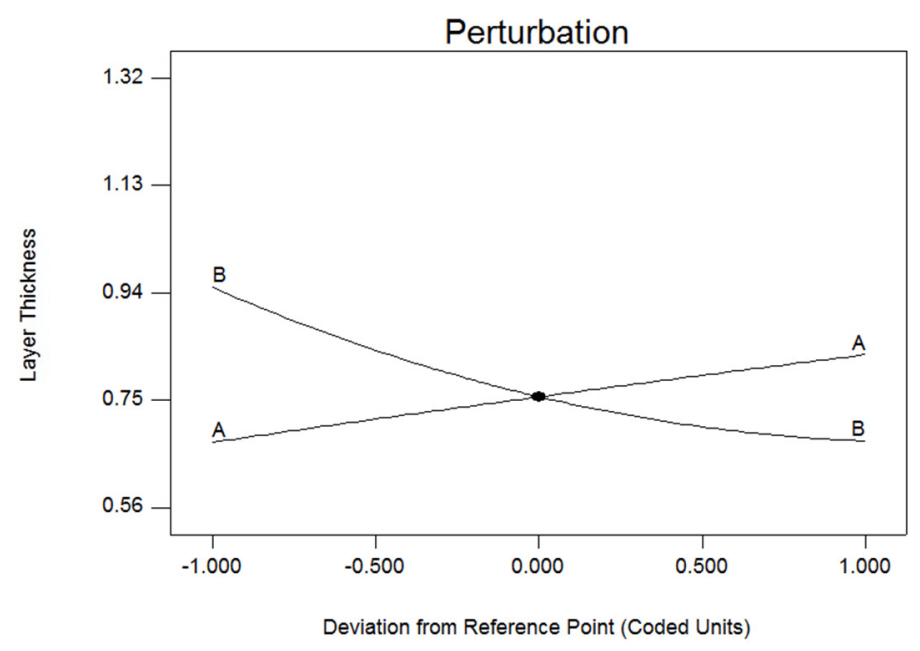

Fig. (8). Perturbation curve for layer thickness model. 
decreasing the laser power to $195 \mathrm{~W}$, the average value of the laser-sintered layer thickness decreased to $0.627 \mathrm{~mm}$. This can be explained by the increase of the amount of energy delivered to ceramic powder surface by increasing the laser power and/or decreasing the laser scanning speed. So decreasing laser scanning speed and increasing laser power are the key factors for maximizing the laser-sintered layer thickness which reduce the consuming time for building up manufacturing.

Moreover, response surface graph illustrates that laser sintered layer thickness is less sensitive to laser power, Figure 9.

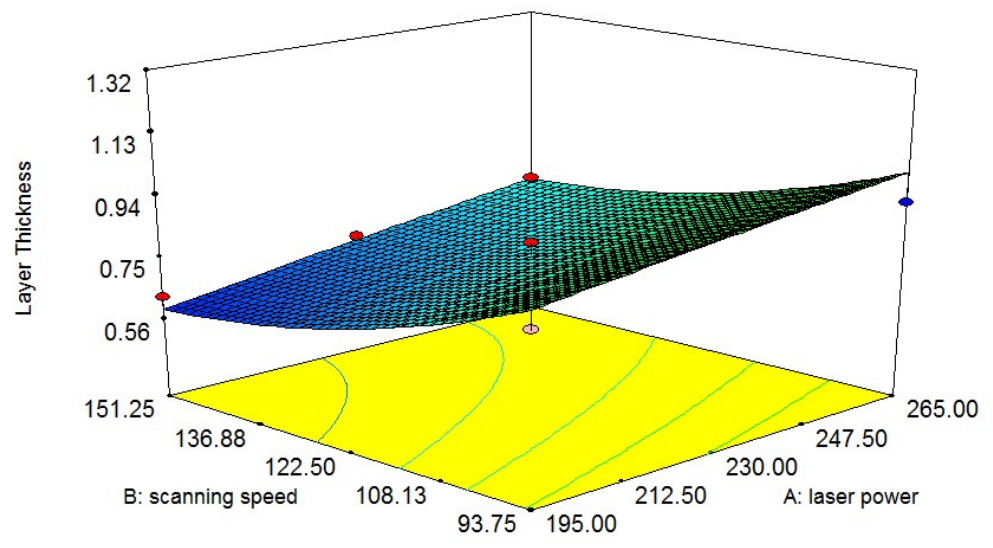

Fig. (9). Response surface for laser-sintered monolayer thickness model.

\section{Laser Sintered Layer Surface Roughness (Ra) Model}

This model is implemented to evaluate the value of the roughness value of the upper surface of the sintered monolayer by calculating the centerline average value parameter Ra. From the layer surface roughness model, it is observed that increasing laser power leads to an increase in surface roughness of laser-sintered layer, however increasing the scanning speed has the opposite effect. At this stage of the investigation, the objective of this model is to minimize the surface roughness of lasersintered layer to have manufactured part with good surface finishing.

Surface roughness model and the model verification are given in analysis of variance, Table 5. The ANOVA ( $F$ test) results indicate that the layer surface roughness is significant model. Where the other model validation measures are given as $\mathrm{R}^{2}=96.98$ $\%$, Adj $\mathrm{R}^{2}=90.93 \%$, Adeq Precision 11.475 .

Consequently, these values indicate that the model can represent the data point easily in the design space with a good accuracy. Figure 10 represents the predicted against actual results on a scatter diagram. The values are following $45^{\circ}$ diagonal, which indicate that the model almost represents a perfect fit of the data points.

Figure 11 shows the perturbation plot for the laser-sintered layer thickness model. It illustrates the overall influence of the control parameters. The layer surface roughness has been found to be directly proportional to the laser power and inversely proportional to laser scanning speed. The average value of the laser-sintered layer surface 
Table 5 : ANOVA table for surface roughness.

\begin{tabular}{c|c|c|c|c|c|l} 
Source & $\begin{array}{c}\text { Sum of } \\
\text { square }\end{array}$ & DF & $\begin{array}{c}\text { Mean } \\
\text { square }\end{array}$ & F value & $\begin{array}{c}\text { P-value } \\
\text { prob }>\text { F }\end{array}$ & \\
\hline Model & 0.91 & 6 & 0.15 & 16.05 & 0.0222 & Significant \\
A & 0.63 & 1 & 0.63 & 66.55 & 0.0039 & \\
B & 0.17 & 1 & 0.17 & 18.10 & 0.0238 & \\
AB & $9.851 \mathrm{E}-003$ & 1 & $9.851 \mathrm{E}-003$ & 1.04 & 0.3827 & \\
A $^{2}$ & $5.895 \mathrm{E}-003$ & 1 & $5.895 \mathrm{E}-003$ & 0.62 & 0.4876 & \\
B $^{2}$ & 0.014 & 1 & 0.014 & 1.51 & 0.3063 & \\
A $^{2}$ B & $9.837 \mathrm{E}-005$ & 1 & $9.837 \mathrm{E}-005$ & 0.010 & 0.9252 & \\
Residual & 0.028 & 3 & $9.465 \mathrm{E}-003$ & & & \\
Cor. total & 0.94 & 9 & & & & \\
\hline
\end{tabular}

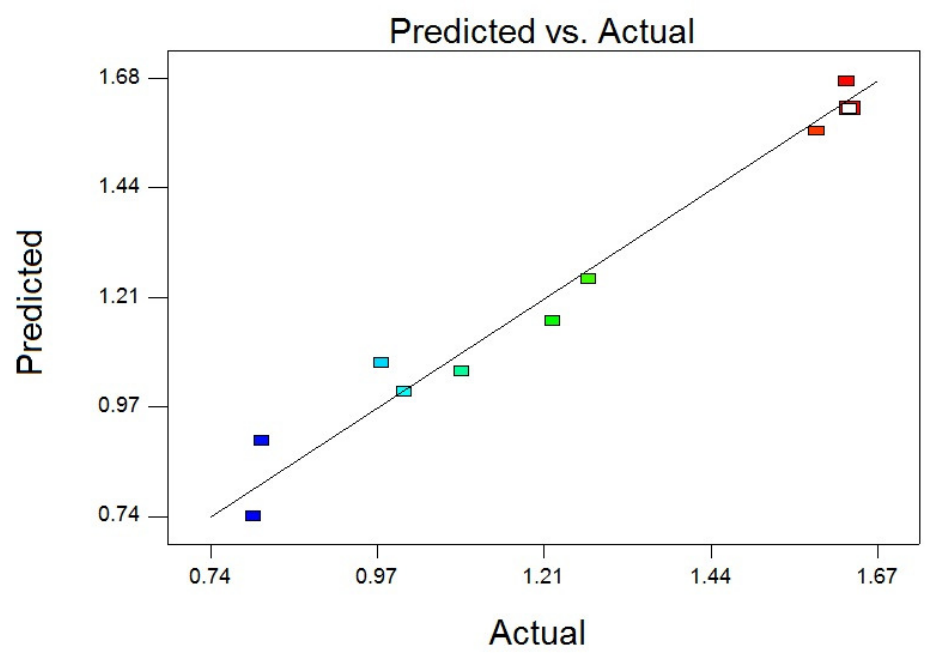

Fig. (10). Predicted and actual values of surface roughness.

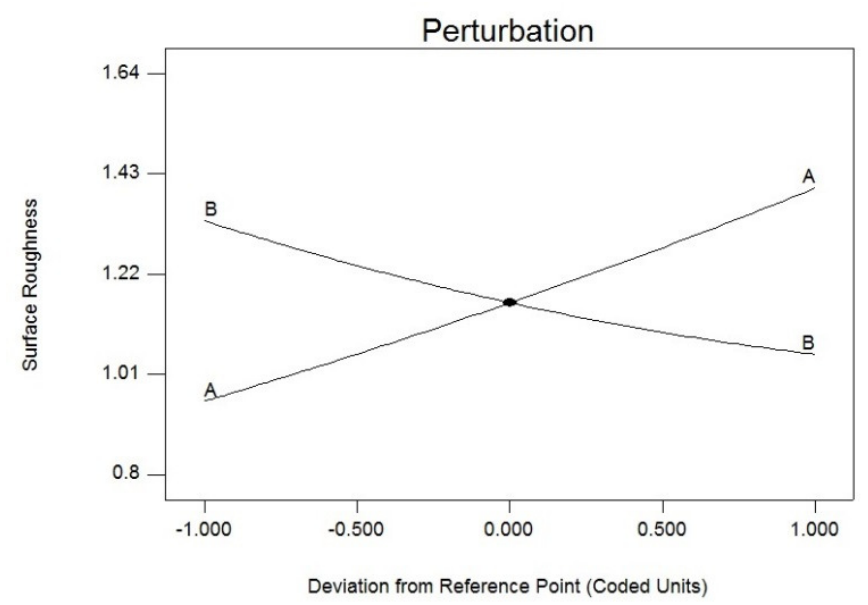

Fig. (11). Perturbation curve for layer surface roughness model. 
roughness $R_{a}$ is more than $1.6 \mu \mathrm{m}$ at a scanning speed of $93.75 \mathrm{~mm} / \mathrm{min}$ and a laser power of $256 \mathrm{~W}$. By increasing the scanning speed to $151.25 \mathrm{~mm} / \mathrm{min}$ and decreasing the laser power to $195 \mathrm{~W}$, the average value of the laser-sintered layer surface roughness $R_{a}$ decreased to $0.8 \mu \mathrm{m}$. This is due to the tendency of molten particles to form larger spherical structures due to their effort to reduce the free enthalpy by optimizing the ratio between the area of free surfaces and the related volume, which cause coarsening [4]. And increase the scanning speed lead to decrease the interacting time between laser and sintered surface, which lead to improve the surface quality by decreasing the possibility of plasma formation [13]. So, increasing the scanning speed and decreasing the laser power are the key factors for minimizing the laser-sintered layer surface roughness, which introduce a good surface finish for manufactured part.

Laser power is more effective than laser scanning speed for improving the layer surface roughness as illustrated by the response surface graph, Fig. (12). It indicates that layer surface roughness change is more sensitive to laser power change at low scanning speed. Also, it is more sensitive to scanning speed change at higher laser power.

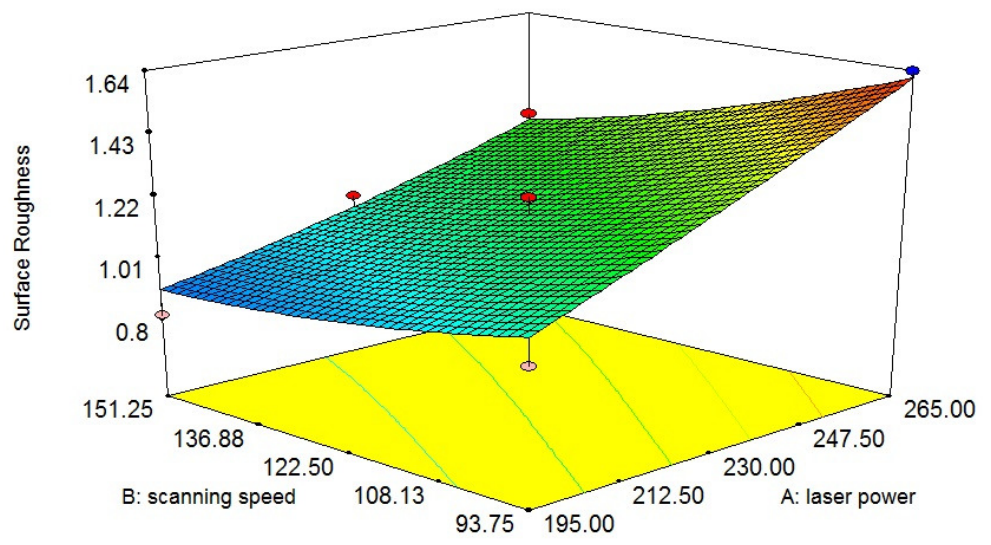

Fig. (12). Response surface for surface roughness model.

\section{Laser-Sintered Part Density Model (DEN.)}

Laser sintered part density, is the ability to introduce a high dense part without voids. So, the objective of the model is to maximize the laser-sintered part density in order to produce dense part with high physical properties and consequently high mechanical properties.

Laser sintered part density model and the model verification are given in the analysis of variance table, Table 6 . The ANOVA results indicate that the model is significant. Validation measures for the model are given as $R^{2}=95.45 \%$, Adj $R^{2}=86.35 \%$, Adeq Precision $=9.752$.

The values indicate that the model can represent the data easily in the design space with a good accuracy. The point distributions on the scatter diagram indicate that the model almost represents a perfect fit of the data points, Fig. (13). 
Table 6 : ANOVA table for density.

\begin{tabular}{c|c|c|c|c|c|c} 
Source & $\begin{array}{c}\text { Sum of } \\
\text { square }\end{array}$ & DF & $\begin{array}{c}\text { Mean } \\
\text { square }\end{array}$ & F value & $\begin{array}{c}\text { P-value } \\
\text { prob }>\text { F }\end{array}$ & Source \\
\hline Model & 0.19 & 6 & 0.031 & 10.49 & 0.0402 & Significant \\
A & $9.198 \mathrm{E}-003$ & 1 & $9.198 \mathrm{E}-003$ & 3.11 & 0.1762 & \\
B & 0.022 & 1 & 0.022 & 7.55 & 0.0709 & \\
A $^{2}$ & 0.086 & 1 & 0.086 & 28.94 & 0.0126 & \\
B $^{2}$ & 0.049 & 1 & 0.049 & 16.48 & 0.0270 & \\
A $^{2}$ B & $7.977 \mathrm{E}-003$ & 1 & $7.977 \mathrm{E}-003$ & 2.69 & 0.1993 & \\
B $^{3}$ & 0.018 & 1 & 0.018 & 6.07 & 0.0906 & \\
Residual & $8.886 \mathrm{E}-003$ & 3 & $2.962 \mathrm{E}-003$ & & & \\
Cor. total & 0.20 & 9 & & & & \\
\hline
\end{tabular}

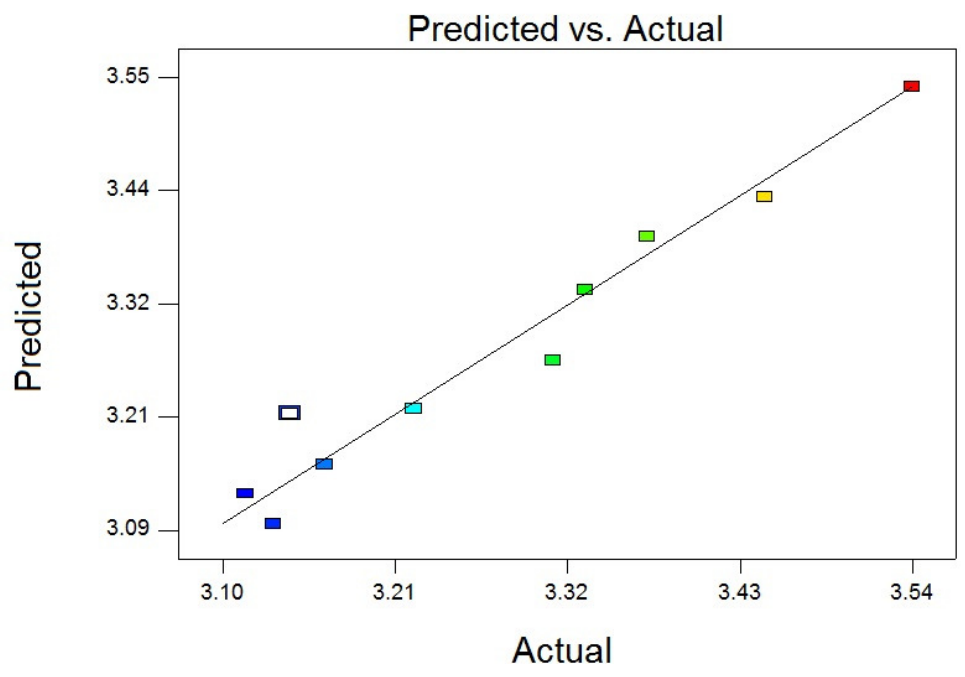

Fig. (13). Predicted and actual values of average density.

Form the perturbation plot, Fig. (14), it is observed that decreasing of scanning speed at constant laser power leads to increase the average density of the laser sintered part but after certain limit the density of the sintered part decreases. The behavior is similar at constant laser scanning speed. By increasing of laser power, the average density will increase, but after certain value of the power the average density of the sintered parts will decrease. The optimization objective is to maximize the laser-sintered part density in order to produce dense part with high physical properties and consequently high mechanical properties. For laser scanning speed of $151.25 \mathrm{~mm} / \mathrm{min}$, the average value of the density is $3.37 \mathrm{gm} / \mathrm{cm}^{3}$ at laser power of $195 \mathrm{~W}$. By increasing the laser power to $230 \mathrm{~W}$, the average value of the density increased to $3.54 \mathrm{gm} / \mathrm{cm}^{3}$ and by additional increase in laser power to $265 \mathrm{~W}$ the average value of the density decreased to $3.33 \mathrm{gm} / \mathrm{cm}^{3}$. While at laser power of $230 \mathrm{~W}$, the average value of the density is 3.16 
$\mathrm{gm} / \mathrm{cm}^{3}$ at scanning speed of $65 \mathrm{~mm} / \mathrm{min}$. By increasing the scanning speed to 151.25 $\mathrm{mm} / \mathrm{min}$, the average value of the density increased to $3.54 \mathrm{gm} / \mathrm{cm}^{3}$ and by additional increase in scanning speed to $180 \mathrm{~W}$ the average value of the density decreased to $3.21 \mathrm{gm} / \mathrm{cm}^{3}$. This is due to the increase of energy delivered into the powder consequently larger melt pools fill up the porous structures of part by increasing laser power and/or decreasing scanning speed. But after certain limit, the density of the sintered part decreases due to over sintering. Over sintering occurs as a result of high temperature or long sintering time result from high laser power or low laser scanning speed and makes the final product quality deterioration, [2]. The dimensions of over sintered parts do not meet the requirement and a few bubbles exit in the interior of the parts due to gases produced which decrease the density. In addition, at very high scanning speed trapped bubbles have not sufficient time to escape from the sintered line due to instant solidification of the sintered layer, as laser interaction time is small.

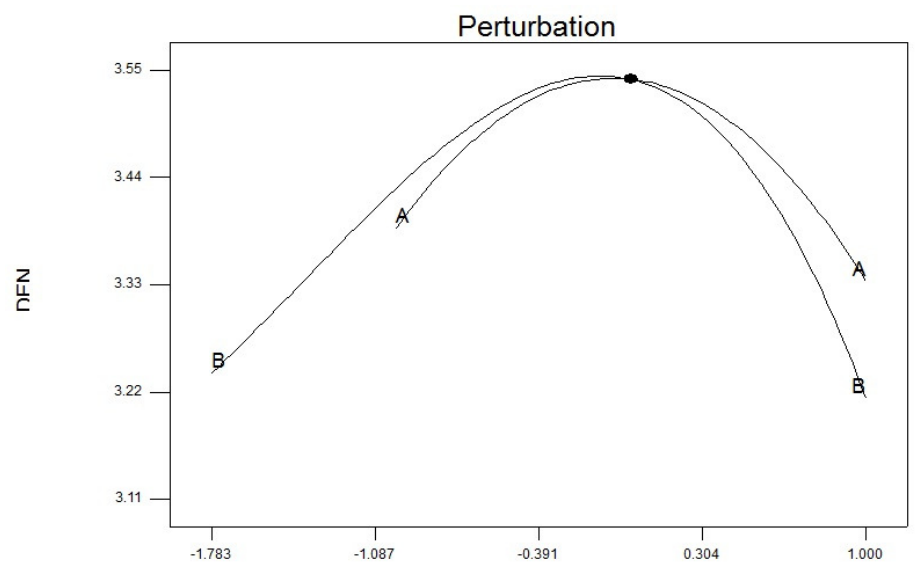

Fig. (14). Perturbation curve for density model.

So optimizing the scanning speed and the laser power are the key factors for maximizing the laser-sintered part density, which improve the physical properties and consequently mechanical properties. Fig. (15) shows the response surface representation for the significant interactions between laser power and laser scanning speed.

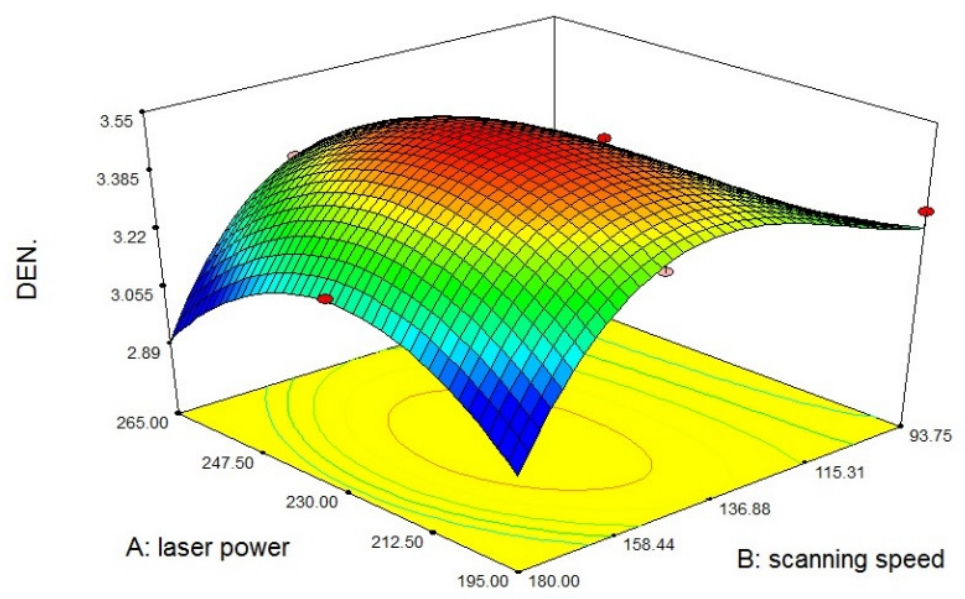

Fig. (15). Response surface for laser sintered part density model. 


\section{Model Governing Equations and Multiple Objective Optimizations}

The final mathematical models in terms of coded factors form are shown in equations $(2: 5)$.The governing equations for the models includes individual and interaction control factors. The developed empirical equations given below can be used to predict the process parameter interactions and their influences on the process quality responses.

$$
\begin{aligned}
& L W=3.17+0.17 A-0.22 B-0.026 A B-0.024 A^{2}+0.029 B^{2} \\
& L T=0.76+0.077 A-0.14 B+9.5 \times 10^{-3} A B-2.903 \times 10^{-3} A^{2}+0.057 B^{2} \\
& R a=1.16+0.22 A-0.14 B-0.050 A B+0.017 A^{2}+0.032 B^{2}+5.983 \times 10^{-3} A^{2} B \\
& D E N=3.43-0.027 A+0.23 B-0.069 A^{2}-0.061 B^{2}-0.11 A^{2} B-0.053 B^{3}
\end{aligned}
$$

\section{Multi-Objective Optimization}

The obtained results show that improving one response may deteriorate the other. For example, increasing the laser power and decreasing laser scanning speed would improve the laser-sintered line width, layer thickness, part density, whilst it worsens the surface roughness. This contradiction can be resolved with multi objective optimization. The objective of the optimization process is to find out the most desirable factors to achieve the specified optimization criteria for the all responses. Optimization is achieved through an objective function called desirability. Each criteria such (maximization or minimization) has a specific importance factor according to its significance on the final laser sintered part properties. This value is specified for each optimization criterion. The laser-sintered part density model is given the highest importance, whilst the surface roughness is given lower importance level than the density. Then the laser sintered line width and layer thickness is given the lowest importance level.

The strategy for optimization was to start at a random point, and proceeded up through steepest slope to reach the peak point (maximum or minimum) according to the optimization criteria. In order to satisfy multi-objective optimization, desirability is defined by the geometric mean of all individual desirability. It ranges from ' 0 ' for least desirable settings and 1 for the most desirable process. Equation 6 represents the total desirability function, such that $\xi$ is the total desirability, $n$ is the number of responses, and $d_{i}$ is the $i^{\text {th }}$ response desirability value.

$$
\xi=\prod_{i=1}^{n} d_{i}
$$

The criterion of the optimization process is to maximize laser-sintered line width, maximize laser-sintered layer thickness, minimize the surface roughness and maximize the density of the laser sintered part. Fig. (16) shows the desirability function values obtained for the objective model. The desirability maximum value of $76.8 \%$ leads to optimal laser power of $230 \mathrm{~W}$ and optimal laser scanning speed of 151.25 $\mathrm{mm} / \mathrm{min}$. The corresponding response values are laser-sintered line width of 2.978 
$\mathrm{mm}$, the layer thickness of $0.678 \mathrm{~mm}$, surface roughness $\left(R_{a}\right)$ of $1.05228 \mu \mathrm{m}$ and the density of $3.54086 \mathrm{gm} / \mathrm{cm}^{3}$.

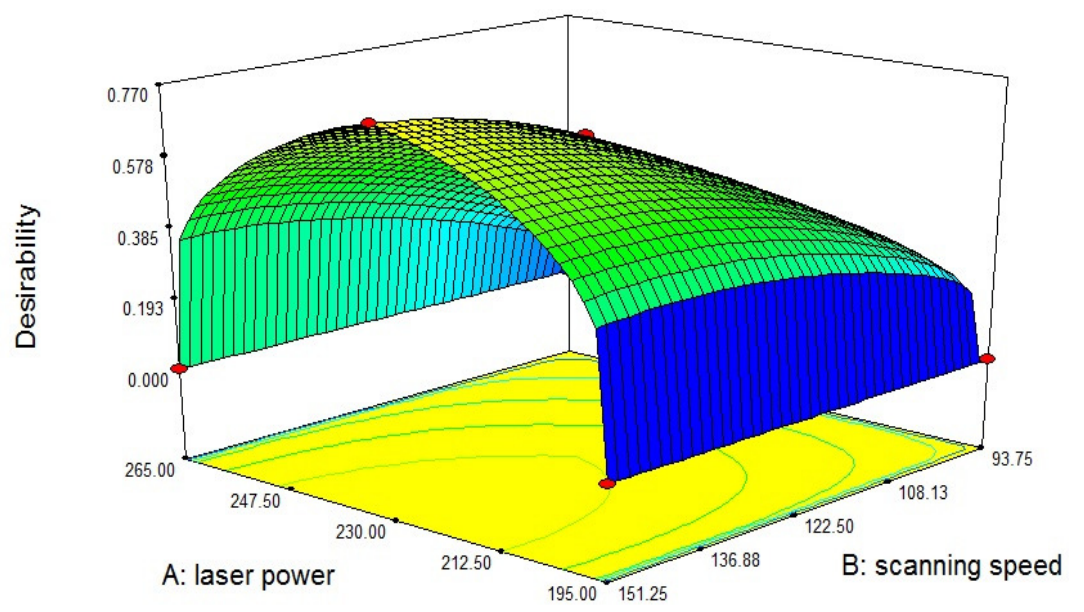

Fig. (16). Desirability shape function.

\section{Verification Experiment for the Model Results}

The reliability of the modeling results is evaluated with follow up laser sintering tests using the optimum parameters obtained with maximum desirability solution. The actual output responses were measured and compared to the model predicted values under the same conditions. The model predicted values and the obtained experimental values for responses are compared in Table 7 , for evaluating the reliability of the model results. The model represents an average accuracy of more than $98.6 \%$.

Table 7 : Predicted - actual results comparison.

\begin{tabular}{c|c|c|c|c} 
Responses & $\begin{array}{c}\text { Monolayer } \\
\text { width }(\mathrm{mm})\end{array}$ & $\begin{array}{c}\text { Monolayer } \\
\text { thickness }(\mathrm{mm})\end{array}$ & $\begin{array}{c}\text { Surface } \\
\text { roughness }(\mu \mathrm{m})\end{array}$ & $\begin{array}{c}\text { Density } \\
\left(\mathrm{gm} / \mathrm{cm}^{3}\right)\end{array}$ \\
\hline Predicted value & 2.979 & 0.677 & 1.05374 & 3.546 \\
Experimental results & 2.974 & 0.689 & 1.09154 & 3.54086 \\
Model accuracy \% & 99.8 & 98.2 & 96.5 & 99.8 \\
\hline Average accuracy & \multicolumn{3}{|c|}{98.6} \\
\hline
\end{tabular}

\section{CONCLUSION}

Ceramic laser sintering has been successfully conducted with a $330 \mathrm{~W}$ pulsed $\mathrm{Nd}$ : YAG fiber laser. The present investigation has clearly demonstrated the importance of 
laser power and laser scanning speed in controlling the ceramic laser-sintered parts quality and physical properties. The results show that laser power and laser scanning speed have direct relationship and inverse relationship respectively with line width, layer thickness and surface roughness however, they have a fluctuating influence on the part density. A statistical modeling and multi-variable optimization are performed to obtain the values control parameter leading to achieve the optimal values of the responses. These optimal control parameters are laser power of $230 \mathrm{~W}$ and laser scanning speed of $151.25 \mathrm{~mm} / \mathrm{min}$ provide a density of the laser-sintered part of $3.54086 \mathrm{gm} / \mathrm{cm}^{3}$ with surface roughness (Ra) of $1.05228 \mu \mathrm{m}$, layer thickness of $0.67 \mathrm{~mm}$ and line width of $2.978 \mathrm{~mm}$. These values are corresponding to the value of total desirability reaches to $76.8 \%$.

\section{REFERENCES}

[1] K. Shahzad, J. Deckers, J.-P. Kruth, and J. Vleugels, "Additive manufacturing of alumina parts by indirect selective laser sintering and post processing," Journal of Materials Processing Technology, vol. 213, pp. 1484-1494, 2013.

[2] W. Wang, S. Ma, J. Fuh, L. Lu, and Y. Liu, "Processing and characterization of laser-sintered Al2O3/ZrO2/SiO2," The International Journal of Advanced Manufacturing Technology, vol. 68, pp. 2565-2569, 2013.

[3] Y. Elshaer, "Fracture of Ceramic/Metal Laminates," PhD dissertation, School of materials, Manchester institute of science and technology (UMIST), 2003.

[4] C. Ader, "Direct Laser Sintering of Ceramics," State of the Art Report, Fraunhofer Institute of Production Technology IPT, Aachen, Germany.

[5] I. Shishkovsky, I. Yadroitsev, P. Bertrand, and I. Smurov, "Alumina-zirconium ceramics synthesis by selective laser sintering/melting," Applied Surface Science, vol. 254, pp. 966-970, 2007.

[6] H.-C. Yen, M.-L. Chiu, and H.-H. Tang, "Laser scanning parameters on fabrication of ceramic parts by liquid phase sintering," Journal of the European Ceramic Society, vol. 29, pp. 1331-1336, 2009.

[7] U. Lakshminarayan, "Selective laser sintering of ceramic materials," Dissertation Abstracts International(USA), vol. 53, p. 215, 1992.

[8] X. Tian, Rapid prototyping of ceramics by direct laser sintering: PapierfliegerVerlag, 2010.

[9] Z. Liu, J. J. Nolte, J. Packard, G. Hilmas, F. Dogan, and M.-C. Leu, "Selective laser sintering of high-density alumina ceramic parts," in Proceedings of the 35th international MATADOR conference, 2007, pp. 351-354.

[10] P. Bertrand, F. Bayle, C. Combe, P. Gœuriot, and I. Smurov, "Ceramic components manufacturing by selective laser sintering," Applied Surface Science, vol. 254, pp. 989-992, 2007.

[11] A. S. E. Elmesalamy, "Narrow Gap Laser Welding of 316L Stainless Steel for Potential Application in the Manufacture of Thick Section Nuclear Components," $\mathrm{PhD}$ disertation, The University of Manchester, School of Mechanical, Aerospace and Civil Engineering, 2013

[12] K. Benyounis and A. Olabi, "Optimization of different welding processes using statistical and numerical approaches-A reference guide," Advances in Engineering Software, vol. 39, pp. 483-496, 2008. 
[13] A. Elmesalamy, L. Li, J. Francis, and H. Sezer, "Understanding the process parameter interactions in multiple-pass ultra-narrow-gap laser welding of thicksection stainless steels," The International Journal of Advanced Manufacturing Technology, vol. 68, pp. 1-17, 2013.

[14] G. E. Box and K. Wilson, "On the experimental attainment of optimum conditions," Journal of the Royal Statistical Society. Series B (Methodological), vol. 13, pp. 1-45, 1951.

[15] S. Leigh, K. Sezer, L. Li, C. Grafton-Reed, and M. Cuttell, "Statistical analysis of recast formation in laser drilled acute blind holes in CMSX-4 nickel superalloy," The International Journal of Advanced Manufacturing Technology, vol. 43, pp. 1094-1105, 2009.

[16] N. Murugan and R. Parmar, "Effects of MIG process parameters on the geometry of the bead in the automatic surfacing of stainless steel," Journal of Materials Processing Technology, vol. 41, pp. 381-398, 1994.

[17] E. Anawa and A.-G. Olabi, "Using Taguchi method to optimize welding pool of dissimilar laser-welded components," Optics \& Laser Technology, vol. 40, pp. 379-388, 2008.

[18] P. Palani and N. Murugan, "Optimization of weld bead geometry for stainless steel claddings deposited by FCAW," Journal of Materials Processing Technology, vol. 190, pp. 291-299, 2007. 